\title{
Asymptomatic iris metastasis of small-cell lung cancer
}

\author{
Shoichi Fukui $\cdot$ Yusuke Takagi Noriko Ozaki $\cdot$ Yoshiro Nakahara \\ Makiko Akahane - Yusuke Okuma - Yukio Hosomi • Mari Iguchi · \\ Tatsuru Okamura $\cdot$ Tsunekazu Hishima $\cdot$ Masahiko Shibuya
}

Received: 8 December 2011/ Accepted: 21 February 2012/Published online: 6 April 2012

(C) The Japan Society of Clinical Oncology 2012

\begin{abstract}
A 70-year-old man was diagnosed with smallcell lung cancer (SCLC) of the left upper lobe, with a TNM classification of cT4N3M1b (PUL, OSS, BRA, HEP). A single asymptomatic brain metastasis $1 \mathrm{~cm}$ in diameter was also identified. The patient underwent four cycles of cisplatin plus irinotecan therapy, with a total effect of partial response. Complete remission of the brain metastasis was also achieved, and whole-brain radiation therapy (WBRT) was postponed at the request of the patient. Six months after diagnosis, he was admitted to our hospital with a major complaint of dizziness. Computed tomography showed enlargement of the primary lesion and multiple brain metastases. WBRT was started, but performance status did not improve. While undergoing WBRT, the patient complained of blurred vision. The ophthalmologist found a metastasis on the right iris by chance, although blurred vision was caused by detachment of the left retina. Two months later, the patient died of respiratory failure. Autopsy histologically confirmed the iris metastasis of SCLC. Cases of iris metastasis diagnosed before death are rarely reported. Iris metastases are estimated to account for $9 \%$ of uveal metastases. This may suggest that many iris
\end{abstract}

S. Fukui · Y. Takagi $(\bowtie) \cdot$ Y. Nakahara $\cdot$ M. Akahane .

Y. Okuma · Y. Hosomi - M. Iguchi · T. Okamura · M. Shibuya Department of Thoracic Oncology, Tokyo Metropolitan Cancer and Infectious Diseases Center Komagome Hospital, 18-22, Honkomagome 3-chome, Bunkyo, Tokyo 113-8677, Japan e-mail: ytakagi-tmd@umin.net

\section{N. Ozaki}

Department of Ophthalmology, Tokyo Metropolitan Cancer and Infectious Diseases Center Komagome Hospital, Bunkyo, Japan

\section{T. Hishima}

Department of Pathology, Tokyo Metropolitan Cancer and Infectious Diseases Center Komagome Hospital, Bunkyo, Japan metastases have few clinical signs and are difficult to diagnose. Asymptomatic iris metastases, particularly among patients with SCLC, are thus likely to be underdiagnosed. Ocular metastasis should be considered when a cancer patient complains of visual disturbance.

Keywords Small-cell lung cancer - Iris metastasis · Diagnosis

\section{Introduction}

Small-cell lung cancer (SCLC) is a tumor with poor prognosis characterized by rapid progression and early metastasis. Ocular metastasis is not uncommon in autopsy cases, but is rarely diagnosed before death. We report a rare case of iris metastasis diagnosed premortem in a patient with SCLC, and discuss with reference to the literature.

\section{Case report}

A 70-year-old man presented to a local hospital with a 1-month history of non-productive cough and chest pain. The patient had smoked 25 cigarettes daily for 50 years. A tumor in the left upper lobe was seen on computed tomography (CT) and transbronchial lung biopsy (TBLB) revealed SCLC. SCLC was diagnosed with a TNM classification of cT4N3M1b (PUL, OSS, BRA, HEP).

The patient reported intermittent pain in the right chest and subcutaneous bleeding in the left upper arm. Performance status (PS) was 2. Laboratory data showed elevated levels of carcinoembryonic antigen, neuron-specific enolase, and progastrin-releasing peptide. A single, asymptomatic brain metastasis, measuring $1 \mathrm{~cm}$ in diameter, was identified. 


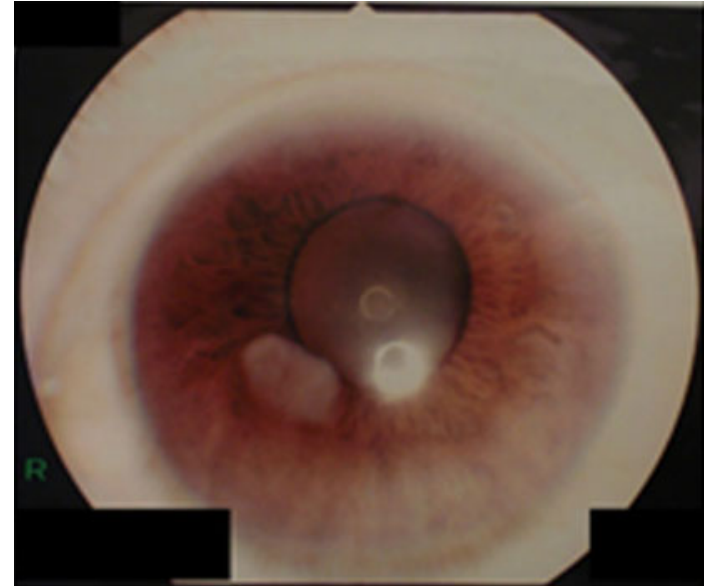

Fig. 1 A pale yellow lesion with irregular margins, $2 \mathrm{~mm}$ in size, at the 1 o'clock meridian on the right iris

The patient was referred to our hospital, then underwent 4 cycles of chemotherapy comprising cisplatin $\left(60 \mathrm{mg} / \mathrm{m}^{2}\right)$ plus irinotecan $\left(60 \mathrm{mg} / \mathrm{m}^{2}\right)$. The total effect of chemotherapy was partial response. Complete remission of the brain metastasis was also achieved, and whole-brain radiation therapy (WBRT) was postponed at the request of the patient.

Six months after initial diagnosis, he was admitted to our hospital with a major complaint of dizziness. CT showed enlargement of the primary lesion and multiple brain metastases. WBRT (30 Gy) was therefore performed, with administration of corticosteroids and glycerol infusion, but performance status did not improve. Further chemotherapy was therefore suspended and palliative treatment was initiated.

While undergoing WBRT, the patient complained of blurred vision. The ophthalmologist found detachment of the retina in the left eye, which was regarded as the cause of blurred vision. By chance, a pale yellow lesion with irregular margins was found at the 1 o'clock meridian on the right iris (Fig. 1). Visual acuity was 0.15 oculus dexter (OD) and 0.4 oculus sinister (OS). Intraocular pressure (IOP) was $13 \mathrm{mmHg}$ OD and $12 \mathrm{mmHg}$ OS. Results of electroretinography were normal. Although no malignant cells were detected in the anterior humor aqueous of the right eye, the ophthalmologist diagnosed the lesion as iris metastasis of SCLC on the basis of its characteristic appearance.

The iris tumor was followed closely without treatment, because the lesion appeared asymptomatic. The iris metastasis increased in size, but symptoms did not worsen. Two months later, a total of 10 months after initial diagnosis of SCLC, the patient died of respiratory failure due to carcinomatous lymphangiosis. Autopsy was performed with the consent of his attorney, and the diagnosis of iris
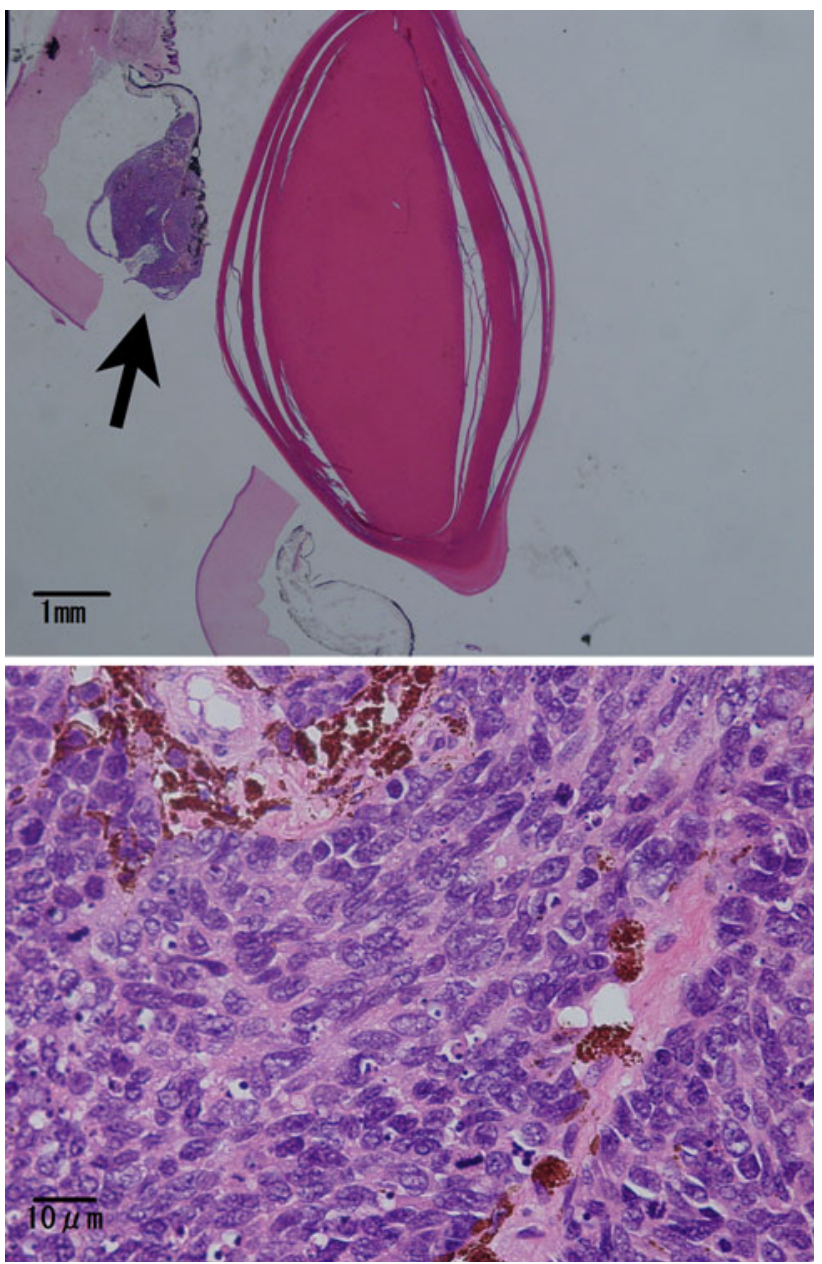

Fig. 2 Histopathology of the iris metastasis. H\&E stain, $\times 40$ (top) and $\times 400$ (bottom)

metastasis was confirmed histologically (Fig. 2). In addition, choroidal metastasis was found in the right eye.

\section{Discussion}

Ocular metastases are seen on autopsy in $9-12 \%$ of patients with any type of cancer $[1,2]$. Uveal metastases are the most common ocular metastases, and choroidal metastases account for $88 \%$ of all uveal metastases [3]. Iris metastases are estimated to account for $9 \%$ of uveal metastases [4]. Metastases on the anterior segment of the eye (iris or ciliary body) occur much less frequently than those on the choroid, because the arterial distribution to the posterior uvea is more abundant. The most common sources of iris metastases are lung and breast cancers [5].

Symptoms of metastatic ocular tumor include decreased vision, visible mass, redness of the eye, pain, and secondary glaucoma [6]. Iris metastasis often appears as a yellowish-white nodule in the inferior quadrant. The 
Table 1 Iris metastases of lung cancer reported in the past 10 years

Only articles written in English are included on this table

$S C L C$ small-cell lung cancer

a This case

\begin{tabular}{llll}
\hline Author & Number of patients & Histology & Symptoms \\
\hline Chen [10] & 1 & Adenocarcinoma & Pain, blurred vision \\
Sui [11] & 1 & Adenocarcinoma & Blurred vision, discomfort \\
Harvey [12] & 1 & Adenocarcinoma & Pain, blurred vision \\
Soysal [13] & 2 & Unknown & Unknown \\
Moura [14] & 1 & SCLC & Pain \\
Roenhorst [8] & 1 & SCLC & None \\
Kesen [15] & 1 & SCLC & Pain \\
Alacacioğlu [16] & 1 & SCLC & Pain \\
Nakashima [9] & 1 & SCLC & Blurred vision \\
Fukui & & SCLC & None \\
\hline
\end{tabular}

differential diagnosis of iris tumor includes amelanotic melanoma, amelanotic nevus, granulomatous iritis, lymphoma, leukemia, and leiomyoma [5].

Diagnosis of metastasis is comparatively easy if the patient has already been diagnosed with cancer. If a patient with an iris nodule has not been diagnosed with cancer after full examination, fine needle biopsy would be useful [7]. For patients with SCLC who present with visual disturbance, carcinoma-associated retinopathy (CAR) syndrome, paraneoplastic optic neuritis, visual disturbance caused by brain metastasis, and chemotherapy-induced optic neuropathy should also be considered as differential diagnoses. In this case, no findings indicated these complications.

Treatment of iris metastasis varies according to the systemic control of primary cancer. In general, systemic chemotherapy is the first choice in most cases. If local control of iris metastasis is not achieved after chemotherapy, or iris metastasis is the only the lesion indicating progression, radiotherapy to the iris metastasis may be a rational choice. A case with iris metastasis of SCLC successfully treated by external beam radiotherapy has already been reported [8]. Enucleation is recommended only if the eye becomes blind and painful [5]. Intravitreal bevacizumab, a monoclonal antibody against vascular endothelial growth factor, has been reported as effective for iris metastasis of SCLC with neovascular glaucoma [9]. Median survival for patients with iris metastasis from lung cancer is 4 months (range 1-18 months) [5].

Few cases of iris metastases diagnosed before death have been reported (Table 1), although $7.1 \%$ of lung cancer patients reportedly show choroidal metastases at autopsy [17]. SCLC cases diagnosed with asymptomatic iris metastasis before death are extremely rare. This may be because many ocular metastases cause no symptoms.

In conclusion, we speculate that cases of iris metastasis are likely to be underdiagnosed. Asymptomatic iris metastases are rarely diagnosed before death, and metastasis to the eye should be considered when a cancer patient complains of visual disturbance.
Conflict of interest The authors declare that they have no conflict of interest.

\section{References}

1. Nelson CC, Hertzberg BS, Klintworth GK (1983) A histopathologic study of 716 unselected eyes in patients with cancer at the time of death. Am J Ophthalmol 95:788-793

2. Small W Jr (1998) Management of ocular metastasis. Cancer Control. 5:326-332

3. Shields CL, Shields JA, Gross NE et al (1997) Survey of 520 eyes with uveal metastases. Ophthalmology 104:1265-1276

4. De Potter P (1998) Ocular manifestations of cancer. Curr Opin Ophthalmol 9:100-104

5. Shields JA, Shields CL, Kiratli $H$ et al (1995) Metastatic tumors to the iris in 40 patients. Am J Ophthalmol 119:422-430

6. Ferry AP, Font RL (1975) Carcinoma metastatic to the eye and orbit II. A clinicopathological study of 26 patients with carcinoma metastatic to the anterior segment of the eye. Arch Ophthalmol 93:472-482

7. Shields CL, Manquez ME, Ehya $\mathrm{H}$ et al (2006) Fine-needle aspiration biopsy of iris tumors in 100 consecutive cases: technique and complications. Ophthalmology 113:2080-2086

8. Roenhorst AW, van den Bergh AC, van Putten JW et al (2007) Iris metastasis in small-cell lung carcinoma. J Thorac Oncol. $2: 1128-1129$

9. Nakashima C, Keino H, Watanabe $\mathrm{T}$ et al (2011) Intravitreal Bevacizumab for iris metastasis of small-cell lung carcinoma with neovascular glaucoma. Jpn J Ophthalmol 55:80-81

10. Chen KH, Hsu WM, Wu CC (2003) Increased interleukin-6 in aqueous humor of a patient with lung-metastatic intraocular adenocarcinoma. Am J Ophthalmol 135:237-239

11. Sui RF, Zhao JL, Zhang SH et al (2005) Metastatic tumor to the iris and ciliary body as an initial sign of lung cancer: a case report. Chin Med J 118:1131-1133

12. Harvey BJ, Grossniklaus HE, Traynor MP (2011) Metastatic lung adenocarcinoma to the iris mimicking Cogan-Reese syndrome. J Glaucoma [Epub ahead of print]

13. Soysal HG (2007) Metastatic tumors of the uvea in 38 eyes. Can $\mathbf{J}$ Ophthalmol 42:832-835

14. Moura LR, Yang YF, Ayres B et al (2006) Clinical, histologic, and immunohistochemical evaluation of iris metastases from small cell lung carcinoma. Can J Ophthalmol 41:775-777

15. Kesen MR, Edward DP, Ulanski LJ et al (2008) Pulmonary metastasis masquerading as anterior uveitis. Arch Ophthalmol 126:572-574 
16. Alacacioğlu A, Oztop I, Fidan F et al (2008) Diabetes insipidus caused by pituitary gland metastasis accompanied by iris metastasis of small cell lung cancer: case presentation and review of the literature. Tumori 94:765-768
17. Kreusel KM, Wiegel T, Stange M et al (2002) Choroidal metastasis in disseminated lung cancer: frequency and risk factors. Am J Ophthalmol 134:445-447 